\title{
O Estatuto da Cidade e a democratização das políticas urbanas no Brasil
}

The City and the Democratisation of Urban Policies in Brazil

Le Statut de la Ville et la démocratisation des politiques urbaines au Brésil

Leonardo Avritzer

\section{OpenEdition}

\section{Journals}

Edição electrónica

URL: http://journals.openedition.org/rccs/4491

DOI: $10.4000 /$ rccs. 4491

ISSN: $2182-7435$

Editora

Centro de Estudos Sociais da Universidade de Coimbra

Edição impressa

Data de publição: 1 Dezembro 2010

Paginação: 205-221

ISSN: 0254-1106

Refêrencia eletrónica

Leonardo Avritzer, «O Estatuto da Cidade e a democratização das políticas urbanas no Brasil », Revista Crítica de Ciências Sociais [Online], 91 | 2010, colocado online no dia 01 novembro 2012, criado a 30 abril 2019. URL : http://journals.openedition.org/rccs/4491 ; DOI : 10.4000/rccs.4491 


\section{LEONARDO AVRITZER}

\section{O Estatuto da Cidade e a democratização das políticas urbanas no Brasil}

O Brasil tem passado por um fortíssimo movimento de democratização do acesso a
terra urbana e de regulamentação do uso da mesma. A origem destes processos está
na organização do movimento pela reforma urbana nos anos 80 e sua atuação com
êxito na Assembléia Nacional Constituinte. Neste artigo, iremos em primeiro lugar
discutir a emergência e as principais características do movimento da reforma urbana
no Brasil. Analisamos em detalhe como a relação entre as associações da sociedade
civil e os atores políticos foi se modificando durante a luta pela reforma urbana no
Brasil. Em segundo lugar, mostramos como a participação surgiu no campo das lutas
pela reforma urbana e como ela gerou uma legislação participativa sobre o assunto
ao longo do período da formulação da Constituição e no período imediatamente
posterior. Em terceiro lugar, mostramos como o requisito de Planos Diretores Urbanos
foi implementado nas cidades de São Paulo, Belo Horizonte, Porto Alegre e Salvador.

Palavras-chave: Brasil; cidades; desenvolvimento urbano; processos participativos; reforma urbana; sociedade civil.

O Estatuto da Cidade e os Planos Diretores Municipais são resultado do surgimento de um forte movimento pela reforma urbana no Brasil no começo da democratização do país. Esse movimento envolveu a formação do MNRU (Movimento Nacional da Reforma Urbana), a elaboração da emenda popular pela reforma urbana submetida à Assembléia Nacional Constituinte em 1987-1988 e uma batalha posterior de 13 anos, que levou à aprovação do Estatuto da Cidade. Esses são os resultados mais importantes da luta pela reforma urbana no Brasil, que conduziu à democratização das políticas urbanas no país e à geração de capacidade de regulação urbana nas grandes cidades brasileiras.

O Movimento pela Reforma Urbana no Brasil e a nova legislação participativa sobre a reforma urbana tiveram origem no forte processo de crescimento urbano do Brasil entre 1950 e 1980. A reforma urbana já estava na agenda da esquerda brasileira e dos setores progressistas da sociedade civil no final do primeiro período democrático (1946-1964). Em 1963, reuniu-se 
em Petrópolis no Hotel Quitandinha a primeira Conferência Nacional pela Reforma Urbana. No entanto, com o golpe de Estado em 1964, a reforma urbana teve que esperar quase 20 anos de autoritarismo antes de voltar à agenda política da sociedade civil brasileira. No final dos anos 70 e começo dos anos 80 , os últimos anos do período autoritário levaram à reconstituição de uma sociedade civil democrática no Brasil. Na maior parte das cidades surgiu também a questão da relação entre as legais e ilegais, motivada pela reorganização de centena de associações de moradores nas regiões Sul, Sudeste e em parte da região Nordeste do país. Uma associação nacional, o MNRU, surgiu no começo do processo de democratização brasileira e continuou a atuar em todo o processo de debates sobre a reforma urbana (1982-2001). Depois da promulgação da Constituição de 1988, o MNRU tornou-se FNRU (Fórum Nacional da Reforma Urbana), efetivamente reinventando a sua política de alianças, até que finalmente conseguiu aprovar o assim chamado Estatuto da Cidade no ano de 2001.

Neste artigo, iremos em primeiro lugar discutir a emergência e as principais características do movimento da reforma urbana no Brasil. Iremos analisar em detalhe como a relação entre as associações da sociedade civil e os atores políticos foi se modificando durante a luta pela reforma urbana no Brasil. Em segundo lugar, iremos mostrar como a participação surgiu no campo das lutas pela reforma urbana e como gerou uma legislação participativa sobre o assunto ao longo do período da formulação da Constituição de 1988 e no período imediatamente posterior. Finalmente, iremos mostrar como o requisito de Planos Diretores Urbanos foi implementado nas cidades de São Paulo, Belo Horizonte, Porto Alegre.

\section{A emergência da luta pela reforma urbana}

A reorganização do movimento pela reforma urbana se deu no começo dos anos 80 , à medida que a democratização brasileira avançava e o regime autoritário entrava em colapso. O MNRU foi originalmente formado nessa época, com o propósito de elaborar uma legislação sobre a reforma urbana para ser apresentada à Assembléia Nacional Constituinte. A sua composição inicial envolveu movimentos populares, associações de moradores, organizações não governamentais e sindicatos (Brasil, 2004), portanto um híbrido entre a sociedade civil e os lobbies organizados. Tal como outros movimentos sociais urbanos que surgiram no Brasil no começo dos anos 80, foi capaz de mobilizar um amplo espectro de atores sociais (Doimo, 1995). No entanto, desde a sua formação, o MNRU também contou com o apoio de um conjunto de associações profissionais de engenheiros e arquitetos envolvidos na política urbana e organizados nacionalmente. A sua 
composição foi, neste sentido, atípica em relação à de outros movimentos da sociedade civil brasileira neste período, não somente devido ao peso das associações profissionais, mas também pela maneira como ele juntou estas associações às organizações locais da sociedade civil (incluindo tanto associações locais como a FAMERJ [Federação das Associações de Moradores do Rio de Janeiro] e o Movimento de Defesa dos Favelados, como também o IAB [Instituto dos Arquitetos do Brasil] e o Instituto dos Engenheiros). Entre o pequeno número de organizações não governamentais existentes naquele período, as mais influentes, a FASE e o Instituto Polis, participaram da formação do MNRU (vide tabela 1).

TABELA 1 - Composição do MNRU

\begin{tabular}{|l|l|}
\hline \multicolumn{1}{|c|}{ Tipo de organização } & \multicolumn{1}{|c|}{ Membro } \\
\hline Movimento popular & $\begin{array}{l}\text { Movimento de Defesa dos Favelados, Famerj (Federação das } \\
\text { Associações de Moradores do Rio de Janeiro) }\end{array}$ \\
\hline ONGs & FASE e POLIS \\
\hline Sindicatos & $\begin{array}{l}\text { Federação Nacional dos Engenheiros e Federação Nacional dos } \\
\text { Arquitetos }\end{array}$ \\
\hline Assoc. Profissionais & ANSUR \\
\hline
\end{tabular}

Fonte: Brasil, 2004

A Assembléia Nacional Constituinte no Brasil foi convocada pelo presidente José Sarney logo após a redemocratização em 1985. A especificidade do acesso da população ao processo constituinte no Brasil se deu através da aceitação de emendas populares. Dezenas de emendas foram apresentadas com um total de 12 milhões de assinaturas, entre elas a emenda popular da reforma urbana proposta à Comissão de Sistematização da Assembléia Nacional Constituinte (Whitaker, 2003). O MNRU propôs uma emenda da Reforma Urbana baseada nos seguintes princípios:

- O direito à cidade, que faz parte da própria ampliação de direitos na tradição legal brasileira (Saule Jr., 1995: 23). Ele introduz por um lado a idéia de que a tradição de direitos é uma tradição ampliável e por outro a idéia de uma integração entre as lutas urbanas e a luta pela saúde, pelo transporte, pelo saneamento e pela educação. Nas palavras de um dos atores sociais do período, "a reforma urbana fará com que se tornem viáveis a unificação... dos movimentos de transporte, de saúde, de habitação, da luta pela terra, permitindo a eles elaborar uma plataforma unificada para a cidade". 
- A subordinação da propriedade privada aos objetivos da política urbana. As cidades brasileiras, antes de 1988, prescindiam tanto dos instrumentos fiscais quanto dos instrumentos administrativos para organizar os grandes interesses imobiliários no seu interior. A emenda popular da reforma urbana propôs os seguintes instrumentos de regulação: o imposto progressivo sobre a propriedade urbana, o imposto sobre o valor agregado da mesma, a preferência do Estado no processo de expropriação da terra urbana. Nas palavras de um importante ator social do período: a reforma urbana irá "politizar o debate sobre o planejamento ao trazer para o centro do debate a função da questão social da propriedade" (Rolnik, 1997).

- Democratização da cidade. A emenda popular introduziu diversos instrumentos para o exercício da governança democrática, entre eles o estabelecimento de audiências públicas, da iniciativa popular, do veto popular à legislação com o apoio de pelo menos $5 \%$ do eleitorado. Assim, o MNRU propôs um cardápio diferenciado de formas de deliberação, algumas delas de iniciativa popular e outras visando ratificação pública de propostas feitas pelo governo. Esse será o elemento democrático mais importante a ser introduzido pelo Estatuto da Cidade em 2001.

A emenda popular da Reforma Urbana foi apresentada à Assembléia Nacional Constituinte com 31 mil assinaturas e desencadeou uma forte disputa com os setores conservadores e os interesses imobiliários. O comitê temático da Constituinte sobre assuntos urbanos e transporte não atraiu inicialmente deputados constituintes com maior visibilidade. É possível afirmar que os setores conservadores naquele momento estavam pressionados por questões mais relevantes de curto prazo, tal como a duração do mandato do presidente Sarney. O Centrão, o grupo conservador que assumiu a tarefa de rever fortemente a proposta feita pela assim chamada "Comissão de Sistematização", tentou transferir a decisão final sobre assuntos urbanos para uma outra arena posterior à Constituinte ao propor a não aplicação automática da nova legislação (Saule Jr., 1995: 28). A maior parte das propostas do subcomitê de assuntos urbanos não foi alterada, mas passou a estar subordinada ao requisito de as cidades possuírem um Plano Diretor Urbano. Assim, o parágrafo $1^{\circ}$ do artigo 182 da Constituição de 1988 torna obrigatórios Planos Diretores Municipais em todas as cidades com mais de 20 mil habitantes (Brasil, 1988). Todas as propostas de reforma urbana foram tornadas dependentes do preenchimento dessa condição. O MNRU foi parcialmente exitoso em tornar a proposta de reforma urbana parte do texto constitucional. Incorporou a gestão democrática da política urbana e a função social da propriedade em princípios amplos adotados pela constituição. No entanto, tais princípios ficaram vinculados ao requerimento 
de elaboração de Planos Diretores Municipais, cuja regulamentação exigia a elaboração de uma legislação infraconstitucional. A conseqüência de tal condição foi a necessidade de uma batalha congressual de mais 13 anos para a aprovação do assim chamado Estatuto da Cidade.

Logo após a Assembléia Nacional Constituinte, o MNRU se transformou no FNRU. Essa mudança teve como motivo um debate sobre as características organizacionais da sociedade civil, tendo em vista a batalha legislativa no Congresso Nacional. A luta pela reforma urbana no Congresso Nacional criou uma nova forma de relação entre sociedade civil e sociedade política. $\mathrm{O}$ estreito relacionamento que houve no período da Constituinte entre o PT e o FNRU jamais teria sido capaz de garantir a aprovação da legislação sobre o Estatuto da Cidade. Portanto, o que vemos nesse caso foi a evolução gradual do FNRU para uma estratégia suprapartidária com a presença de organizações com forte estrutura nacional.

Nos anos posteriores à promulgação da Constituição de 1988 surgiram 16 projetos de lei sobre a regulamentação do capítulo sobre a Política Urbana. Já nesse momento foi possível perceber que o alinhamento automático entre a sociedade civil e os partidos de esquerda não ocorrera. O projeto de lei que iria se tornar o Estatuto da Cidade foi o projeto 181 de 1990, proposto pelo senador Pompeu de Sousa, um conhecido jornalista do Rio de Janeiro, também conhecido pela sua forte ligação à Editora Abril. Pompeu de Sousa não era considerado um membro de esquerda do parlamento brasileiro. No entanto, o seu projeto de lei continha os seguintes elementos da proposta feita pelo FNRU: o direito coletivo à cidade, a coordenação do processo de ocupação da terra urbana, a função social da propriedade, a taxação progressiva da propriedade urbana e a demanda de Planos Diretores Municipais nas cidades com mais de 20 mil habitantes. Apesar destes elementos, este projeto de lei ficava aquém das propostas do FNRU em um conjunto de questões, em particular aquelas que dizem respeito à gestão democrática da cidade. A atuação do MNRU durante a Constituinte previa um conjunto de instrumentos para a gestão das cidades, entre os quais a iniciativa popular de legislação, o veto popular à legislação urbana e o direito à informação (Silva, 1990). O Projeto de Lei Pompeu de Sousa previu uma versão bastante restritiva da participação popular. No seu artigo 10, previa que a política urbana seria dirigida com base na gestão democrática e no incentivo à participação popular para a formulação e implementação de projetos de desenvolvimento urbano.

O Projeto de Lei Pompeu de Sousa tornou-se altamente polêmico. Os setores conservadores não estavam felizes com o fato de ele reinserir na agenda política parte da agenda do movimento da reforma urbana já tratada 
durante a Assembléia Nacional Constituinte. Por outro lado, os setores da sociedade civil (especialmente o FNRU) também não estavam satisfeitos com algumas das formulações do projeto de lei, em especial com a diluição das formas democráticas de gestão urbana das cidades. Inicialmente, como resposta ao Projeto Pompeu de Sousa, o FNRU em aliança com o PT, o PC do B e com outros setores da esquerda progressista propôs um outro projeto de lei, apresentado pela deputada do PT-ES Lourdinha Savignon. A disputa entre atores da sociedade civil e setores conservadores no congresso revela assim estratégias importantes empregadas para a implementação da participação. Inicialmente, tanto setores conservadores quanto setores progressistas tinham o seu próprio projeto. No entanto, na medida em que o processo legislativo avançou ambos os setores se concentraram no mesmo, inserindo no seu interior a questão da gestão democrática da cidade.

O Projeto de Lei Pompeu de Sousa permaneceu em suspenso no congresso até 1997, altura em que foi aprovado na primeira das comissões, a Comissão de Desenvolvimento Econômico, Indústria e Comércio. O parecer emitido por aquela comissão foi bastante conservador, eliminando todos os aspectos participativos do projeto de lei. O FNRU respondeu, propondo submeter o Estatuto da Cidade à Comissão de Assuntos do Consumidor e Meio Ambiente, que tinha forte presença da esquerda. Muitos dos elementos progressistas do Estatuto da Cidade foram, nessa comissão, incorporados no Projeto de Lei Pompeu de Sousa, entre os quais valeria a pena ressaltar: o direito à cidade, entendido enquanto prerrogativa de elaboração da legislação urbana, que havia sido rejeitado pela CEIC, e os direitos ligados à preempção, que permitiam à administração pública desapropriar terra urbana em áreas de possível expansão das cidades.

Podemos então perceber como a batalha entre o FNRU e os setores conservadores na área de políticas urbanas se desenvolveu. De um lado, o Projeto de Lei Pompeu de Sousa tornou-se ponto de referência na elaboração da legislação infraconstitucional sobre a reforma urbana, mas não incorporou completamente a agenda do FNRU no que diz respeito à participação nas políticas urbanas. De outro lado, após reinserir essas demandas no Projeto de Lei Pompeu de Sousa na Comissão de Assuntos do Consumidor e Meio Ambiente, o projeto de lei foi encaminhado à comissão mais importante do Congresso Nacional, a Comissão de Constitucionalidade e Justiça. O relatório final sobre a legalidade do Projeto Pompeu de Sousa, aprovado no ano 2000, problematizou a constitucionalidade de dois itens importantes, a saber: se o governo federal tem a prerrogativa de tornar a participação local obrigatória e a ceder o direito especial de uso de terras públicas. Em uma audiência pública o FNRU defendeu os instrumentos de cessão de uso 
especial para fins de moradia, assim como o princípio da função social da propriedade. O último desafio do FNRU foi como reinserir a participação democrática na versão final do projeto de lei. Dois parlamentares do PT pediram para que o FNRU interviesse sobre essa questão e depois disso uma nova emenda ao projeto de lei foi aprovada, requerendo audiências públicas na elaboração de Planos Diretores Municipais (Arruda, 2001). Assim, a agenda participativa da sociedade civil concentrou-se, na parte final do processo, na capacidade de ratificação em audiências públicas da proposta de Plano Diretor apresentada pelas administrações locais. Essa demanda, tornada suprapartidária, virou o ponto central da agenda democratizante do movimento pela reforma urbana no Brasil.

\section{A implementação do Estatuto da Cidade: Porto Alegre, Belo Horizonte e São Paulo}

A existência de uma legislação nacional sobre política urbana não tornou tais políticas homogêneas no país. Pelo contrário, as diferentes tradições de movimentos sociais urbanos e as diferentes coalizões políticas continuaram atuando fortemente na implementação de políticas urbanas. Nesta segunda parte deste artigo iremos mostrar como a diferente configuração da sociedade civil e da sociedade política afetaram os Planos Diretores Municipais em três cidades: Porto Alegre, Belo Horizonte e São Paulo.

\section{Porto Alegre e a antecipação dos instrumentos do Estatuto da Cidade}

O primeiro caso que trataremos como exemplar no que diz respeito à implementação de planos diretores urbanos é o caso de Porto Alegre. Este é exemplar por diferentes motivos: Porto Alegre tem a mais longa tradição de planejamento urbano do Brasil, com a elaboração de um plano diretor na área de tráfego ainda nos anos 50; é também exemplar porque a cidade elaborou um plano diretor urbano ainda nos anos 70, apontando antes de outras cidades brasileiras para a necessidade de planos diretores urbanos; finalmente a cidade é exemplar também pela antecipação de políticas que irão aparecer em outras cidades brasileiras logo após a aprovação do Estatuto das Cidades. Neste sentido, as tentativas da cidade de produzir um plano diretor urbano datam ainda do período autoritário, no qual um embrião de plano diretor separou as áreas rurais das áreas urbanas da cidade e incorporou alguns embriões da idéia de participação política.

O PDM de Porto Alegre permaneceu em vigor por mais de 20 anos. Durante este período, novos problemas se colocaram, em especial o parcelamento contínuo da terra urbana e a impossibilidade de legalizar ocupações de terras públicas. Estes problemas, que apareceram durante os debates da 
Assembléia Nacional Constituinte e da elaboração do Estatuto da Cidade, receberam ao longo do tempo em Porto Alegre uma resposta capaz de qualificar a cidade como um caso exemplar de democratização da política urbana. Durante os 16 anos nos quais a cidade foi administrada pelo Partido dos Trabalhadores, a questão da subdivisão da terra urbana e da distribuição de títulos de propriedade para os ocupantes de terras públicas marcou sempre forte presença na agenda política da administração municipal. Ainda em 1991, a cidade diferenciou o seu estoque permanente de terreno urbano destinado às áreas verdes do estoque de terras destinado à legalização de ocupações ilegais. A lei de ocupação do solo urbano em Porto Alegre também passou a prever concessões coletivas de uso da terra urbana. Em 1994 a cidade constituiu um fundo para o planejamento urbano, parte do qual tinha sido constituído pela venda de propriedades urbanas. Assim, Porto Alegre antecipou instrumentos que uma boa parte das cidades brasileiras apenas passaria a utilizar depois da aprovação do Estatuto da Cidade.

De notar também que, nesta cidade, o sistema judicial não bloqueou as tentativas de legalizar a ocupação do solo pela população de baixa renda da cidade. O sistema legal do Rio Grande do Sul interpretou a legislação existente de forma progressista, posicionando-se a favor da legalidade da cessão do direito de uso da terra urbana à população de baixa renda da cidade. Em 1995, o Corregedor Geral da Justiça emitiu uma instrução normativa, autorizando a legalização deste tipo de ocupação. O Tribunal de Justiça do Rio Grande do Sul confirmou esse posicionamento do corregedor. Finalmente, o Supremo Tribunal Federal confirmou a legalidade da decisão.

O consenso que emergiu em Porto Alegre acerca da legalidade da cessão de direito de uso sobre terras públicas começou a ser construído em 1993 no primeiro Congresso da Cidade. Ali foram discutidas de forma participativa as orientações gerais para o desenvolvimento da cidade. O Plano Diretor Municipal de Porto Alegre foi elaborado em 1995-1996 e enviado naquele ano para a câmara dos vereadores. No ano de 1996, que foi um ano eleitoral, as associações comunitárias da cidade demandaram mais debate sobre o PDM, o que foi aceito pela nova administração do Partido dos Trabalhadores, que retirou o PDM da Câmara dos Vereadores assim que ela assumiu o poder (Guimaraens, 2001). Esses debates envolveram novas audiências públicas realizadas na cidade, que geraram novos limites para construções. O PDM voltou à Câmara dos Vereadores e foi aprovado em 5 de Novembro de 1999.

Um dos avanços principais contido no novo plano diretor de Porto Alegre foi a incorporação de mecanismos internos de revisão, a serem aplicados na 
medida em que a cidade se desenvolve e tem a sua população aumentada. O fato de Porto Alegre ter tido um PDM desde 1979 criou na cidade a percepção da rapidez das mudanças no cenário urbano do Brasil e da falta de mecanismos da administração municipal para lidar com tais mudanças. Como reação tentou-se que o PDM de Porto Alegre criasse uma percepção totalizante da cidade e mecanismos para controlar de forma equilibrada o processo de mudança do cenário urbano, de forma a dar à cidade alternativas entre a falta total de controle dos processos urbanos e o controle total dos processos urbanos. Esta é a origem do Conselho de Desenvolvimento Urbano e Ambiental, que tem como objetivos: a revisão permanente do PDM, a prerrogativa de propor novas maneiras de criar terra urbana e a deliberação sobre questões ligadas ao meio ambiente. Assim, Porto Alegre parece ser um caso interessante justamente pela capacidade de antecipar aspectos do debate urbano em grandes cidades brasileiras. A maior parte dos instrumentos urbanos utilizados pela cidade antecipa instrumentos posteriormente introduzidos pelo Estatuto da Cidade.

\section{Belo Horizonte: a regulação urbana negociada}

Belo Horizonte é um segundo caso bem-sucedido de regulação urbana, embora com características muito diferentes das de Porto Alegre. Belo Horizonte, a primeira cidade planejada do Brasil, fundada nos últimos anos do século XIX, teve um planejamento que repetiu os erros cometidos nas principais cidades brasileiras. Tal como no Rio de Janeiro e em São Paulo, não foram reservados espaços suficientes para as habitações da população de baixa renda e, algumas décadas depois da fundação da cidade, já estava em curso um processo de favelização na mais nova capital brasileira (Martins, 1991). Ao contrário do Rio de Janeiro e de Porto Alegre, Belo Horizonte conseguiu, durante a vigência do regime autoritário no Brasil, deslocar a população de baixa renda para regiões distantes da região central e com pouca infraestrutura urbana. No entanto, o crescimento habitacional vertiginoso entre 1960 e 1980, uma vez que a população aumentou quase seis vezes, tornou as áreas centrais saturadas. Assim, dois problemas simultâneos foram criados: de um lado, a expansão excessiva da área ocupada pela cidade, em virtude principalmente da detenção de áreas intermediárias por grandes proprietários de terras urbanas; e, de outro, a necessidade de adensar e regular a expansão das regiões centrais da cidade. Todos estes desafios se colocaram para a administração do Partido dos Trabalhadores a partir de 1993.

Imediatamente após a posse, o prefeito Patrus Ananias instalou uma comissão encarregada de elaborar uma proposta de Plano Diretor Municipal. 
Esta comissão foi constituída inicialmente por pessoal técnico da prefeitura e apenas depois da sua elaboração os principais atores urbanos, como o SINDUSCON, que reúne os grandes construtores de Belo Horizonte, foram convidados a discutir e se posicionar sobre o plano. Foram realizadas audiências públicas em cada uma das nove regiões de Belo Horizonte e, a partir daí, o plano foi enviado para a Câmara dos Vereadores, que organizou uma grande audiência pública para toda a cidade (Mendonça, 2006). Quase todos os instrumentos propostos para o PDM de Belo Horizonte foram aprovados, nomeadamente: a instituição do mecanismo de solo criado, que passou a regular a relação entre a administração municipal e os grandes interesses urbanos; a criação do conceito de zona de adensamento, que permitiu à cidade direcionar as zonas de crescimento demográfico; e o instituto da operação urbana, que permitiu a coordenação de grandes ações de intervenção urbana entre a administração municipal e os grandes interesses privados. Assim, diferentemente de Porto Alegre, Belo Horizonte tem um PDM que regula a atividade urbana, mas que também negoceia fortemente com os interesses constituídos, antecipando alguns dos mecanismos do Estatuto da Cidade.

O grande elemento específico do processo de implantação do PDM de Belo Horizonte foi o estabelecimento de um prazo de carência de 6 meses para a sua entrada em vigor. Este aspecto, que não vemos presente em outros PDMs, mostra a especificidade do Plano Diretor de Belo Horizonte - a geração de um processo interno de negociação entre a prefeitura e os grandes proprietários de terras urbanas na cidade. Não houve, no caso de Belo Horizonte, uma presença muito forte do poder judiciário, seja para legalizar formas de cessão do uso da terra urbana (como no caso de Porto Alegre), ou para bloquear ações do Estado, como aconteceu, como iremos ver mais abaixo, no caso de São Paulo. No caso do PDM de Belo Horizonte a grande característica é um processo interno de negociação com os proprietários, que obedeceu a duas lógicas: de um lado, os interesses urbanos imediatos não foram contrariados devido à cláusula de seis meses de carência; de outro, a cidade passou a contar, depois do prazo de carência, com um forte instrumento de regulação urbana.

São Paulo: regulação da cidade em conflito com os interesses privados urbanos Dos três casos de PDM que estamos discutindo neste artigo, o mais desafiador do ponto de vista da regulação urbana é o de São Paulo. Diferentemente de Porto Alegre e de Belo Horizonte, a cidade de São Paulo expressa conflitos muito mais intensos e interesses muito mais organizados na sua estrutura urbana. Durante a primeira administração do Partido dos Trabalhadores 
na cidade, entre 1989 e 1992, a prefeita Luíza Erundina chegou a fazer uma proposta de Plano Diretor Municipal que, no entanto, não chegou a ser aprovada pela Câmara Municipal. Depois de oito anos de gestões conservadoras ligadas ao grupo de Paulo Maluf, o Partido dos Trabalhadores voltou a dirigir a cidade no ano de $2001 .{ }^{1}$

Uma das primeiras medidas da administração de Marta Suplicy foi elaborar um Plano Diretor Municipal para a cidade. Para isso, a prefeita nomeou como relator do Plano Nabil Bonduki, um veterano do movimento pela reforma urbana na cidade. Bonduki havia sido professor da FAU, Faculdade de Arquitetura e Urbanismo da Universidade de São Paulo, e Presidente do Sindicato dos Arquitetos, tendo sido eleito vereador na mesma eleição que tornou Marta Suplicy prefeita. A nomeação de Bonduki como relator do PDM de São Paulo mostra a força do movimento pela reforma urbana no interior da administração municipal.

O processo de elaboração do Plano Diretor Municipal de São Paulo envolveu duas fases, sendo a primeira delas a determinação de diretrizes gerais para a elaboração do plano. Ainda em 2002 foram aprovadas sete diretrizes:

- o incentivo à ocupação das regiões intermediárias da cidade visando o adensamento urbano de acordo com o Estatuto da Cidade;

- a escolha de áreas na periferia da cidade que passariam a ser prioritárias no processo de ocupação do solo urbano;

- a legalização de ocupações em áreas públicas;

- a elaboração de incentivos ao transporte urbano;

- incentivos à reocupação das áreas centrais da cidade;

- restauração da permeabilidade do solo urbano;

- aumento das zonas exclusivamente residenciais;

- criação de áreas de preservação cultural.

Todas essas propostas, claramente identificadas com o Movimento da Reforma Urbana e com instrumentos específicos do Estatuto da Cidade, entraram em debate na cidade de São Paulo durante a discussão do Estatuto da Cidade. 26 audiências públicas foram conduzidas pela administração municipal, assim como 15 reuniões com organizações não governamentais e pessoal técnico ligados às políticas urbanas. Mais de 230 organizações participaram neste processo durante o ano de 2002. A parte mais polêmica do processo de aprovação do PDM de São Paulo envolveu a demarcação

\footnotetext{
${ }^{1}$ São Paulo é uma das cidades brasileiras com o maior índice de descontinuidade administrativa. Desde a redemocratização brasileira ela foi governada por partidos de direita e de esquerda, entre eles o PTB, o PT, o PPB e o PSDB e o PFL. Nenhum destes partidos, com exceção do PPB, governou duas gestões em seguida.
} 
dos limites para a construção nos diferentes bairros da cidade. O PDM de São Paulo foi consolidado e enviado à Câmara dos Vereadores, necessitando de 33 votos para ser aprovado. Os vereadores realizaram algumas emendas ao plano, emendas estas que representavam interesses pontuais de grandes especuladores imobiliários. A administração municipal aceitou estas emendas e, com o voto destes vereadores, aprovou o Plano Diretor da cidade de São Paulo.

A segunda fase do processo de aprovação do Plano Diretor Municipal de São Paulo envolveu a elaboração de Planos Diretores Regionais. Essa etapa se mostrou altamente conflituosa, tendo emergido dois conflitos principais na cidade: o primeiro relacionado com a publicação de uma lista sobre mudanças no zoneamento das 31 regiões da cidade que foi publicada no Diário Oficial. Interesses ligados aos setores imobiliários questionaram na justiça imprecisões na lista, que poderiam eventualmente ferir direitos de construção. A lista foi republicada com informações mais precisas e mapas. Em segundo lugar, houve um conflito importante em relação à representação da sociedade civil no momento da realização das 31 audiências públicas previstas por lei. As audiências atraíram três tipos de públicos: profissionais da área de planejamento urbano, representações de associações de bairro que não queriam mudanças radicais nos seus bairros e representantes de grandes especuladores urbanos. Este último grupo não queria estar presente nas audiências e tentou representar-se através de imobiliárias. A administração municipal rejeitou a representação coletiva através de imobiliárias e essa questão também terminou na justiça. O Ministério Público acionou a cidade a pedido das imobiliárias alegando que os seus representados não estavam podendo representar os seus interesses. A justiça aceitou o argumento do Ministério Público, alegando que a exclusão de associações civis contrariava a Constituição. Para a juíza Simone Casasoretti as associações representativas deveriam ter a prerrogativa de participar das audiências (Folha de São Paulo, 2003). Os Planos Diretores Regionais foram aprovados em Julho de 2004, depois que as audiências públicas foram realizadas novamente.

O processo de ratificação do Plano Diretor Municipal e dos planos regionais na cidade de São Paulo mostra a operação de diversos elementos do Estatuto da Cidade: as audiências públicas desempenharam o papel que o FNRU supôs - a inclusão da população no processo decisório - e elementos que o FNRU não supôs - a legalização da representação dos interesses imobiliários. Neste sentido, o Estatuto da Cidade mostrou tanto a capacidade de incentivar o processo participativo na cidade quanto a de legalizar interesses privados. 
É importante comparar o processo de elaboração do PDM de São Paulo com o de Porto Alegre e Belo Horizonte. São Paulo se diferencia de Porto Alegre por ter necessitado dos instrumentos produzidos pelo Estatuto da Cidade para democratizar e regular a sua política urbana. O PDM de São Paulo seria muito mais conservador se o Estatuto da Cidade não tivesse sido aprovado em 2001. Porto Alegre antecipou instrumentos contidos no Estatuto da Cidade, como é o caso da cessão de direito de uso especial para fins de moradia, ao passo que São Paulo necessitou do Estatuto da Cidade para ter este e outros mecanismos. São Paulo se diferencia de Belo Horizonte pela incapacidade da administração municipal de controlar os grandes interesses urbanos sem deixar o processo ser questionado judicialmente. Em Belo Horizonte grandes proprietários urbanos negociaram politicamente com a administração municipal, ao passo que em São Paulo eles utilizaram instrumentos do Estatuto da Cidade para questionar o próprio processo de regulação urbana. Sem o Estatuto da Cidade, São Paulo jamais teria um plano diretor com a regulação dos interesses urbanos.

\section{Estatuto da Cidade, democracia e regulação urbana}

A democracia brasileira criou, ainda que tardiamente, instrumentos para a democratização das cidades. O capítulo sobre a Política Urbana da Assembléia Nacional Constituinte e o Estatuto da Cidade criaram instrumentos de democratização das cidades e de regulação do espaço urbano que as cidades brasileiras necessitavam desde o período democrático anterior (1946-1964). Ainda assim, a implementação destes instrumentos em cada uma das cidades variou de acordo com o governo, a força da sociedade civil, o partido político no governo e a força dos interesses imobiliários. Ao comparar três grandes capitais brasileiras com diferentes tradições de movimentos urbanos foi possível perceber o papel desempenhado pelo Estatuto da Cidade e pelos instrumentos de política urbana instituídos no Brasil democrático. Instrumentos tais como a cessão de direito de uso especial, o direito de preempção, a zona de adensamento e a outorga onerosa permitiram melhorar e democratizar a gestão das grandes cidades brasileiras. No entanto, tal como vimos ao diferenciar os casos de Porto Alegre, Belo Horizonte e São Paulo, a participação da população pode desempenhar diversos papéis. Em Porto Alegre e Belo Horizonte o papel principal da participação popular foi a ratificação de formas de regulação urbana. Em Porto Alegre a participação ocorreu no chamado Congresso da Cidade e em Belo Horizonte em audiência públicas. O local no qual a participação popular pareceu mais contenciosa foi na cidade de São Paulo. Ali, devido à conflituosidade da própria regulação urbana na cidade, a 
organização da sociedade civil teve que fazer frente a interesses imobiliários capazes de se expressar no processo de participação e de questionar alguns dos seus aspectos na esfera legal. Ainda assim, o resultado da participação popular no Plano Diretor de São Paulo foi positivo, na medida em que ratificou instrumentos de regulação urbana na cidade. Neste sentido, podemos afirmar que o papel dos Planos Diretores Municipais é reforçar o aspecto democratizante e regulador urbano em diversas correlações de força entre governo, sociedade civil e interesses privados. Em todos os três casos analisados o Estatuto da Cidade desempenha um papel importante, ainda que este seja mais importante nas situações em que a coalizão entre governo e sociedade civil é fraca ou não existente. Nestes casos, é a força reguladora da legislação, aliada à exigência da participação, que permite controlar interesses privados que na maior parte do século XX brasileiro prevaleceram sem nenhum controle, tanto por parte da sociedade civil quanto do Estado.

\section{Referências bibliográficas}

Brasil (1988), "Constituição da República Federativa do Brasil". Brasília, DF, Senado. Brasil, Flávia de Paula Duque (2004), "Espaços públicos, participação cidadã e renovação nas políticas urbanas locais nos anos 80 ”. Dissertação de Mestrado em Sociologia (Belo Horizonte/MG), FAFICH (Faculdade de Filosofia e Ciências Humanas)/ UFMG (Universidade Federal de Minas Gerais instalada em Belo Horizonte).

Doimo, Ana Maria (1995), A vez e a voz do popular: movimentos sociais e a participação política no Brasil pós-70. Rio de Janeiro: Relume-Dumará, ANPOCS.

Folha de São Paulo (2003), "Planos regionais terão de voltar à discussão", 20 de dezembro, C3.

Martins, Berenice (1991), Cafuas, barracos e barracões. Belo Horizonte cidade planejada. Rio de Janeiro: Iuperj.

Mendonça, Jupira (2006), Entrevista dada a Cláudia Feres sobre o Plano Diretor Municipal de Belo Horizonte.

Rolnik, R. (1997), A Cidade e a Lei - legislação, política urbana e territórios na cidade de São Paulo. São Paulo: Studio Nobel/FAPESP.

Saule Jr., Nelson (1995), "O Direito à cidade na Constituição de 1988. Legitimidade e eficácia do Plano Diretor”. Dissertação de Mestrado em Direito, PUC, São Paulo.

Silva, Ana Amélia (1990), "A luta pelos direitos urbanos: novas representações de cidade e cidadania”, Espaço \& Debates, 10(30), 28-41.

Whitaker, Francisco (2003), "Iniciativa popular de lei: limites e alternativas", in Maria Victoria Benevides, Paulo Vannuchi e Fábio Kerche (2003), Reforma política e cidadania. São Paulo: Perseu Abramo, 182-200. 


\section{Referências eletrônicas}

Arruda, Inácio (2001), "Estatuto da Cidade uma conquista histórica", consultado em 29/05/2006, http://www.inacio.com.br/downloads/ESTATUTO_DA_CIDADE_ SEPARATA_2001.doc.

Estado de São Paulo (2002), "Plano Diretor aprovado inclui mudanças em zonas residenciais", consultado em 20/05/2006, www.estadao.com.br/agestado/ noticias/2002/ ago/23/305.htm.

Guimaraens, Maria Etelvina (2001), "A Competência Municipal e o $2^{\circ}$ PDDUA", consultado em 30/05/2006, http://www.portoalegre.rs.gov.br/planeja/spm2/4.htm.

Saule Jr., Nelson (2005), "O Direito à Cidade como paradigma da governança urbana democrática”, Instituto Polis, http://www.polis.org.br/artigo.

Singer, Paul (1994), São Paulo's Master Plan, 1989-92: The Politics of Urban Space. Washington, D.C.: Woodrow Wilson International Center for Scholars (Comparative Urban Studies Occasional Paper Series; 2), consultado em 05/05/2006, http://www. wilsoncenter.org/index.cfm?topic_id=1410\&fuseaction=topics.publications\&group_ id $=24862$. 